\title{
ВПЛИВ НЕСИМЕТРІЇ ТРИШАРОВИХ ЦИЛІНДРИЧНИХ ОБОЛОНОК 3 ЛЕГКИМ ЗАПОВНЮВАЧЕМ НА ЇХ НАПРУЖЕНО-ДЕФОРМОВАНИЙ СТАН ПРИ НЕСТАЦІОНАРНИХ НАВАНТАЖЕННЯХ
}

\begin{abstract}
Отримано рівняння коливань несиметричної тришарової циліндричної оболонки 3 легким заповнювачем при нестаціонарному навантаженні. При аналізі елементів пружної структури використовується модель теорії оболонок Тимошенка для кожного шару. Числові результати про напруженодеформований стан несиметричної тришарової пружної структури отримані за допомогою методу скінченних елементів. Досліджено вплив фізико-механічних параметрів шарів оболонки на їі напружено-деформований стан при внутрішньому імпульсному навантаженні.

Ключові слова: несиметрична тришарова циліндрична оболонка; легкий заповнювач; нестаціонарне навантаження; напружено-деформований стан; аналіз числових результатів.
\end{abstract}

Вступ. На протязі всієї історії існування техніки спостерігається постійний природній інтерес до досліджень, спрямованих на зменшення матеріалоємності конструкцій нової техніки при одночасному покращенні їх функціональних характеристик і підвищенні їх надійності. Забезпечення таких вимог часто досягається за рахунок використання нових конструкційних матеріалів з більш високими фрізико-механічними, технологічними й експлуатаційними параметрами. Необхідність одночасного виконання цілого ряду часом суперечливих вимог призводить до ідеї розробки багатошарових конструкцій, в яких кожен шар виконує тільки одну або краще кілька фрункцій. При цьому шари можуть відрізнятися як по товщині, так і за фрізико-механічними властивостями, тобто пакет може бути істотно неоднорідний. Досить розповсюджене застосування в техніці знайшли тришарові конструкції у вигляді пластин і оболонок різної геометрії. За своїми властивостями і конструкцією тришарові оболонки поділяються на симетричні і несиметричні. Дослідженню нестаціонарних процесів в симетричних тришарових оболонках присвячено багато робіт $[1,8,11,13]$. Динамічна поведінка тришарових оболонок 3 несиметричною структурою пакету шарів вивчена набагато менше $[3,4$, $9,10]$. Разом з тим такі оболонки є досить жорсткими конструкціями [2], i їх дослідження має як теоретичне, так і практичне значення.

В даній роботі досліджені нестаціонарні коливання несиметричної тришарової циліндричної оболонки з легким заповнювачем при імпульсному внутрішньому навантаженні. Несиметричність даної структури 
складається в тому, що її несучі шари виготовлені з різних матеріалів. Використання заповнювача з легких матеріалів дозволяє при невеликому збільшенні ваги конструкції істотно підвищити її згинальну жорсткість. При значній відмінності фрізико-механічних параметрів шарів доцільно застосовувати теорії оболонок з використанням незалежних гіпотез для кожного із шарів $[5,11]$.

Викладення основного матеріалу дослідження. Задача коливань тришарової несиметричної циліндричної оболонки з легким заповнювачем при симетричному нестаціонарному навантаженні розглянута з використанням «дискретно-структурного» підходу. Для шаруватих оболонок з легким заповнювачем потрібне більш акуратне двовимірне моделювання в порівнянні з багатошаровими оболонками з однаковими геометричними параметрами [5]. Беручи це зауваження до уваги, були використані відповідні гіпотези Тимошенка для оболонок [1].

На основі теорії деформації зсуву переміщення $u_{i}$ і $w_{i}$ у несучих шаpax у напрямку $x$ (поздовжній), $z$ (товщина) та $t$ (час) при малих лінійних переміщеннях виражаються через наступні залежності:

$$
\begin{aligned}
& u_{i}(x, z, t)=u_{0}^{i}(x, t)+z_{i} \psi_{x}^{i}(x, y, t) ; \\
& w_{i}(x, z, t)=w_{0}^{i}(x, y, t), \quad i=1,3,
\end{aligned}
$$

де $z_{i}$ - вертикальна координата кожного несучого шару і вимірюється вгору від серединної поверхні кожного несучого шару; $\psi_{i}-$ кут повороту нормалі до серединної поверхні.

Деформації у несучих шарах:

$$
\begin{aligned}
\varepsilon_{x x}^{i} & =\varepsilon_{0 x x}^{i}+z_{i} k_{x x}^{i}, \quad i=1,3 ; \\
\gamma_{x z}^{i} & =2 \varepsilon_{x z}^{i},
\end{aligned}
$$

де

$$
\varepsilon_{0 x x}^{i}=\frac{\partial u_{0}^{i}}{\partial x}+\frac{w_{0}^{i}}{R} ; \quad \varepsilon_{0 x z}^{i}=\frac{\partial w_{0}^{i}}{\partial x}+\psi_{x}^{i}-\frac{u_{0}^{i}}{R} ; \quad k_{x x}^{i}=\frac{\partial \psi_{i}}{\partial x}, \quad i=1,3 .
$$

Тут $\varepsilon_{0 x x}{ }^{i} ; \varepsilon_{0 x z} ; \varepsilon_{0 z z}{ }^{i}-$ компоненти деформацій серединних поверхонь несучих шарів; $R$ - радіус кривини оболонки.

Поля переміщень для товстого заповнювача, засновані на моделі [6], мають вигляд

$$
\left\{\begin{array}{l}
u_{c}(x, z, t)=\left(1+\frac{z}{R}\right) u_{0}^{c}(x, t)+z_{c} u_{1}^{c}(x, t) ; \\
w_{c}(x, z, t)=w_{0}^{c}(x, t)+z_{c} u_{1}^{c}(x, t) .
\end{array}\right.
$$


Кінематичні залежності для заповнювача для шаруватих оболонок на основі малих деформацій прийняті у вигляді:

$$
\begin{aligned}
& \varepsilon_{x x}^{c}=\frac{1}{\left(1+z / R_{c}\right)}\left(\frac{\partial u_{c}}{\partial x}+\frac{w_{c}}{R_{c}}\right) ; \\
& \gamma_{x z}^{c}=2 \varepsilon_{x z}^{c}=\frac{1}{\left(1+z / R_{c}\right)}\left(\frac{\partial w_{c}}{\partial x}-\frac{u_{c}}{R_{c}}\right)+\frac{\partial u_{c}}{\partial z},
\end{aligned}
$$

де $u_{c}, w_{c}$ - компоненти узагальненого вектора переміщень заповнювача; $E_{c}, \rho_{c}$ - фрізико-механічні параметри заповнювача; $R_{c}$ - приведений радіус заповнювача.

Умови сумісності, які передбачають ідеальне з'єднання між заповнювачем і несучими шарами без відриву і проковзування, представлені в наступному вигляді [7]:

$$
\left\{\begin{array} { l } 
{ u _ { c } ( z = z _ { c i } ) = u _ { 0 } ^ { i } + \frac { 1 } { 2 } ( - 1 ) ^ { k } h _ { c } \psi _ { c } ; } \\
{ w _ { c } ( z = z _ { c i } ) = w _ { 0 } ^ { i } ; }
\end{array} \quad \left\{\begin{array}{l}
\text { Для } i=\rightarrow\left(k=1 ; z_{c 1}=\frac{h_{2}}{2}\right) ; \\
\text { Для } i=\rightarrow\left(k=0 ; z_{c 2}=-\frac{h_{2}}{2}\right),
\end{array}\right.\right.
$$

де $h_{c}$ - товщина заповнювача; $\psi_{c}-$ кут повороту нормалі до серединної поверхні заповнювача.

Рівняння руху для несучих шарів та заповнювача виводяться за варіаційним принципом стаціонарності Гамільтона - Остроградського, згідно якого

$$
\delta \int_{t_{1}}^{t_{2}}(K-\Pi+A) d t=0
$$

де П - повна потенціальна енергія пружної системи; К - повна кінетична енергія пружної системи; А - робота зовнішніх сил; $t_{1}$ i $t_{2}-$ фріксовані моменти часу.

При виводі рівнянь коливань тришарових оболонок з легким заповнювачем незалежному варіюванню підлягають: компоненти переміщень несучих шарів і заповнювача.

Після стандартних перетворень в варіаційному рівнянні (7), з врахуванням співвідношень (1) - (6), отримаємо систему рівнянь руху для тришарової циліндричної оболонки з різними несучими шарами при симетричному імпульсному навантаженні:

$$
N_{x x, x}^{1}+\frac{Q_{x z}^{1}}{R}+\frac{2}{h_{c}^{2}} M_{2 x x, x}^{c}+\frac{4}{h_{c}^{3}} M_{3 x x, x}^{c}+\frac{2}{R_{c} h_{c}^{2}} M_{2 x z}^{c}+\frac{4}{R_{c} h_{c}^{3}} M_{3 x z}^{c}=\rho_{1} h_{1} \frac{\partial^{2} u_{1}}{\partial t^{2}}
$$




$$
\begin{gathered}
N_{x x, x}^{2}+\frac{Q_{x z}^{2}}{R}+\frac{2}{h_{c}^{2}} M_{2 x x, x}^{c}-\frac{4}{h_{c}^{3}} M_{3 x x, x}^{c}+\frac{2}{R_{c} h_{c}^{2}} M_{2 x z}^{c}-\frac{4}{R_{c} h_{c}^{3}} M_{3 x z}^{c}=\rho_{2} h_{2} \frac{\partial^{2} u_{2}}{\partial t^{2}} \\
Q_{x z, x}^{1}-\left(\frac{N_{x x}^{1}}{R}\right)-\frac{R_{c}}{h_{c}}-\frac{1}{R_{c} h_{c}} M_{1 x x}^{c}-\frac{4}{h_{c}^{2}} M_{z}^{c}-\frac{2}{R_{c} h_{c}^{2}} M_{2 x x}^{c}+\frac{1}{h_{c}} M_{1 x z, x}^{c}- \\
-\left(1+\frac{h_{1}}{2 R}\right) P(x, t)=\rho_{1} h_{1} \frac{\partial^{2} w_{1}}{\partial t^{2}} ; \\
Q_{x z, x}^{2}-\left(\frac{N_{x x}^{2}}{R}\right)+\frac{R_{c}}{h_{c}}+\frac{1}{R_{c} h_{c}} M_{1 x x}^{c}-\frac{4}{h_{c}^{2}} M_{z}^{c}-\frac{2}{R_{c} h_{c}^{2}} M_{2 x x}^{c}-\frac{1}{h_{c}} M_{1 x z, x}^{c}=\rho_{2} h_{2} \frac{\partial^{2} w_{2}}{\partial t^{2}} \\
M_{x x, x}^{1}-Q_{x z}^{1}-\frac{h_{1}}{h_{c}^{2}} M_{2 x x, x}^{c}-\frac{2 h_{1}}{h_{c}^{3}} M_{3 x x, x}^{c}-\frac{h_{1}}{R_{c} h_{c}^{2}}-\frac{2 h_{1}}{R_{c} h_{c}^{2}} M_{3 x z}^{c}=\rho_{1} \frac{h_{1}^{3}}{12} \frac{\partial^{2} \psi_{1}}{\partial t^{2}} \\
M_{x x, x}^{2}-Q_{x z}^{2}+\frac{h_{2}}{h_{c}^{2}} M_{2 x x, x}^{c}-\frac{2 h_{2}}{h_{c}^{3}} M_{3 x x, x}^{c}+\frac{h_{2}}{R_{c} h_{c}^{2}} M_{2 x z}^{c}-\frac{2 h_{2}}{R_{c} h_{c}^{2}} M_{3 x z}^{c}=\rho_{2} \frac{h_{2}^{3}}{12} \frac{\partial^{2} \psi_{2}}{\partial t^{2}} \\
N_{x x, x}^{c}-\frac{4}{h_{c}^{2}} M_{2 x x, x}^{c}-\frac{4}{R_{c} h_{c}^{2}} M_{3 x x, x}^{c}+\frac{1}{R_{c}} N_{x z}^{c}-\frac{4}{R_{c} h_{c}^{2}} M_{2 x z}^{c}-\frac{4}{R_{c}^{2} h_{c}^{2}} M_{3 x z}^{c}=\rho_{c} h_{c} \frac{\partial^{2} u_{c}}{\partial t^{2}} \\
M_{1 x x, x}^{c}-N_{x z}^{c}-\frac{4}{h_{c}^{2}} M_{3 x x, x}^{c}+\frac{1}{R_{c}} M_{1 x z}^{c}-\frac{4}{R_{c} h_{c}^{2}} M_{3 x z}^{c}=\rho_{c} \frac{h_{c}^{3}}{12} \frac{\partial^{2} \psi_{c}}{\partial t^{2}} \\
h_{c}^{2} M_{z}^{c}-\frac{1}{R_{c}} N_{x x}^{c}+\frac{4}{R_{c} h_{c}^{2}} M_{2 x x}^{c}-\frac{4}{h_{c}^{2}} M_{2 x z, x}^{c}=\rho_{c} h_{c} \frac{\partial^{2} u_{c}}{\partial t^{2}}
\end{gathered}
$$

де напруження на одиницю довжини для заповнювача можна визначити наступним чином:

$$
N_{x x}^{c}=\int_{-h_{i} / 2}^{h_{i} / 2} \sigma_{x x}^{c} d z_{i}, M_{x x}^{c}=\int_{-h_{i} / 2}^{h_{i} / 2} z_{i} \sigma_{x x}^{c} d z_{i}, Q_{x z}^{c}=k_{s} \int_{-h_{i} / 2}^{h_{i} / 2} \sigma_{x z}^{c} d z_{i},
$$

Тут $P(x, t)$ - розподілене імпульсне внутрішнє навантаження.

Узагальнений закон Гука запишемо наступним чином:

$$
\begin{gathered}
N_{x x}^{i}=E^{i}\left(\varepsilon_{x x}^{i}+v^{i} \varepsilon_{y y}^{i}\right) ; \quad N_{y y}^{i}=E^{i}\left(\varepsilon_{y y}^{i}+v^{i} \varepsilon_{y y}^{i}\right) ; \\
Q_{x z}^{i}=G^{i} \varepsilon_{x z}^{i} ; \quad M_{x x}^{i}=D^{i} \kappa_{x x}^{i}, \quad i=1,2
\end{gathered}
$$




$$
\varepsilon_{x x}^{i}=\frac{\partial u_{i}}{\partial x} ; \quad \varepsilon_{y y}^{i}=\frac{w_{i}}{R} ; \quad \varepsilon_{x z}^{i}=\psi_{x}^{i} ; \quad \kappa_{x x}^{i}=\frac{\partial \psi_{x}^{i}}{\partial x}
$$

При дослідженні коливань несиметричної тришарової циліндричної оболонки з урахуванням легкого заповнювача при жорсткому защемленні країв граничні умови покладалися при $x=0, x=L(L-$ довжина оболонки) у вигляді:

$$
\begin{gathered}
u_{i}(0, t)=0 ; i=\overline{1,3} ; \quad w_{1}(0, t)=w_{3}(0, t)=0 ; \\
u_{i}(L, t)=0 ; i=\overline{1,3} ; \quad w_{1}(L, t)=w_{3}(L, t)=0 .
\end{gathered}
$$

Нульові початкові умови при $t=0$ покладалися:

$$
\begin{gathered}
u_{i}(x, 0)=\frac{\partial U_{i}}{\partial t}(x, 0)=0 ; \quad i=\overline{1,3} ; \\
w_{1}(x, 0)=w_{3}(x, 0)=\frac{\partial w_{1}}{\partial t}(x, 0)=\frac{\partial w_{3}}{\partial t}(x, 0)=0 .
\end{gathered}
$$

Розглянемо тришарову циліндричну оболонку, несиметрія якої заключається в тому, що її несучі шари виготовлені з різних матеріалів. На оболонку діє вісесиметричне внутрішнє імпульсне навантаження у вигляді $P_{3}=A \cdot \sin \frac{\pi t}{t}[\eta(t)-\eta(t-T)]$. В розрахунках покладалося: $A=10^{6} \Pi a ; T=50 \cdot 10^{-6} c$. при наступних геометричних та фрізико-механічних параметрах: $L=0,25 \mu, \quad R=0,20 \mu, L / h_{1}=250 ; h_{1}=h_{3}=0,001 \mathrm{~m}$; $R / h_{1}=200 ; h_{2} / h_{1}=6$.

Відповідні задачі розв'язані методом скінченних елементів.

Розглянемо шість випадків динамічної поведінки тришарової циліндричної оболонки з легким заповнювачем при нестаціонарному навантаженні з урахуванням параметрів, які наведені вище. Отримані числові результати дозволяють характеризувати напружено-деформований стан тришарової пружної структури циліндричного типу в будь-який момент часу на досліджуваному часовому інтервалі згідно вищевказаних постановок. Розрахунки проводилися в інтервалі часу $0 \leq t \leq 40 T$.

Перший випадок. 1 - внутрішній несучий шар, 2 - заповнювач, 3 зовнішній несучий шар; $h_{1}=h_{3}=1$ мм; модуль пружності $E_{1}=7 \cdot 10^{10} \Pi a$; щільність $\rho_{1}=2,7 \cdot 10^{3} \mathrm{kz} / \mathrm{m}^{3}$; коефіцієнт Пуассона $v=0,3 ; h_{2}=6 \mathrm{~m}$; для $h_{2}$ відношення модулів пружності $E_{1} / E_{2}=50 \mathrm{i} E_{1} / E_{2}=500$, щільність $\rho_{2}=25 \kappa 2 / \mathrm{M}^{3}$, коефіцієнт Пуассона $v=0,33$.

Таким чином, маємо симетричну тришарову оболонку з легким заповнювачем, яка навантажена внутрішнім імпульсним тиском. Розглянуті 
два варіанти властивостей легкого заповнювача: перший (1) $-E_{1} / E_{2}=50$ і другий (2) $-E_{1} / E_{2}=500$. На рис. 1 наведені порівняльні графіки максимальних прогинів коливальних процесів в серединній поверхні легкого заповнювача симетричної тришарової циліндричної оболонки $w_{i j}$. Індекс $i$ означає номер випадку розташування шарів ( $i=2)$, а $j$ - номер властивості заповнювача $(j=\overline{1,2})$. Оскільки графіки максимальних прогинів симетричні відносно середини оболонки для випадку жорсткого защемлення країв оболонки, то на лівій частині рисунку наведені графіки прогинів (1), а на правій - (2). Слід зауважити, що максимуми прогинів для симетричного випадку конструкції тришарової структури досягаються для (1) і (2) при $t=7 \mathrm{~T}$.

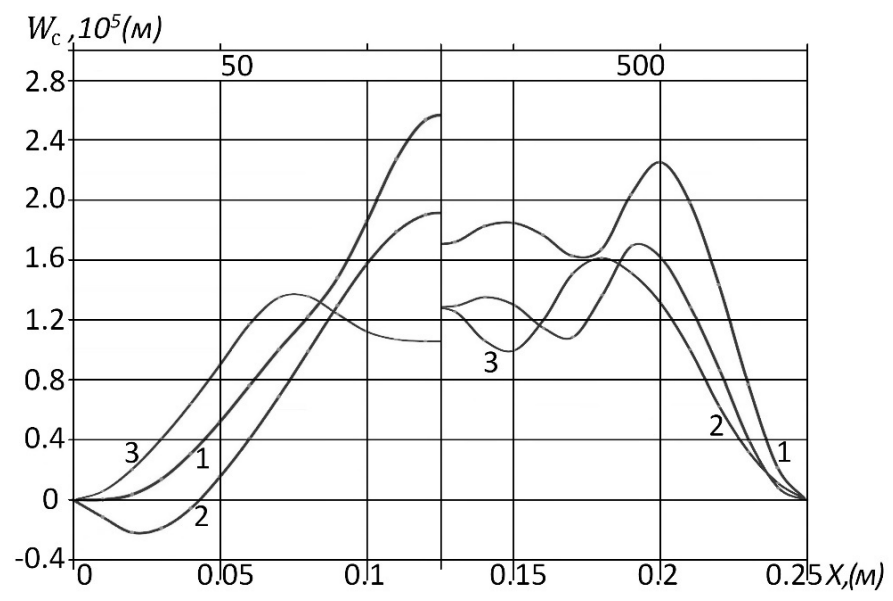

Рис. 1 - Максимальні прогини в серединній поверхні легкого заповнювача тришарової циліндричної оболонки

Аналіз графрічного матеріалу дав можливість зробити наступні висновки: із рис. 1 випливає, що максимальна величина прогинів по просторовій координаті (криві з індексом 1) зі зменшенням відношення $E_{1} / E_{2}$ стає більшою на 14\%; також суттєво змінюється якісна картина характеру коливань, які стають хвилеподібними. Більш суттєва різниця спостерігається для колових напружень по просторовій координаті $\sigma_{y y}^{c}$ (рис. 2). 3 графріків видно, що для співвідношення (1) максимальне значення напруження $\sigma_{y y}^{c}$ досягає значення $11,5 \cdot 10^{5}$ Па (крива з індексом 1, зліва ), а для співвідношення (2) таке ж напруження $\sigma_{y y}^{c}$ в 2,1 рази менше (крива з індексом 1, справа). Хвилеподібний характер коливань зберігається в обох випадках. Треба відзначити, що отримані результати добре узгоджуються з результатами статті [11]. 


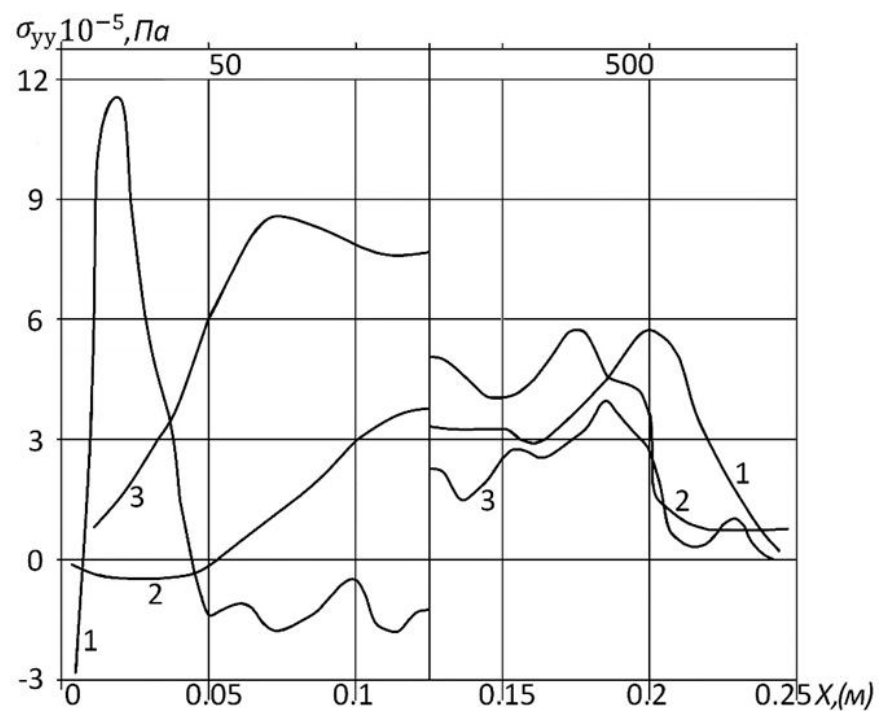

Рис. 2 - Максимальні напруження $\sigma_{y y}^{c}$

в серединній поверхні легкого заповнювача тришарової циліндричної оболонки

Розглянемо другий випадок несиметричної тришарової оболонки 3 легким заповнювачем, яка навантажена внутрішнім імпульсним тиском. Досліджено два варіанти властивостей легкого заповнювача: перший (1) $-\left(E_{1}+E_{3}\right) /\left(2 E_{2}\right)=50$; і другий $(2)-\left(E_{1}+E_{3}\right) /\left(2 E_{2}\right)=500 ; 1$ - внутрішній несучий шар, 2 - заповнювач, 3 - зовнішній несучий шар; $h_{1}=h_{3}=1$ мм; $h_{2}=6 м м$; для $h_{1}$ модуль пружності $E_{1}=7 \cdot 10^{10} \Pi a$; щільність $\rho_{1}=2,7 \cdot 10^{33}$; для $h_{3}$ модуль пружності $E_{3}=2 \cdot 10^{11} \Pi a$; щільність $\rho_{3}=7,8 \cdot 10^{3} \mathrm{kz} / \mathrm{m}^{3}$; коефріцієнти Пуассона $v=0,33$; для $h_{2}$ відношення модулів пружності $\left(E_{1}+E_{3}\right) /\left(2 E_{2}\right)=50 \mathrm{i}\left(E_{1}+E_{3}\right) /\left(2 E_{2}\right)=500$; щільність $\rho_{3}=25 \kappa 2 / \mathrm{m}^{3} \mathrm{M}$ коефіцієнт Пуассона $v=0,3$.

На рис. 1 наведені порівняльні графріки максимальних прогинів коливальних процесів в серединній поверхні легкого заповнювача несиметричної циліндричної оболонки (криві з індексом 2). Криві максимальних прогинів побудовані аналогічно першому випадку. Максимуми прогинів для другого випадку несиметричної конструкції тришарової структури досягаються при (1) $t=5,15 T$, а для (2) при $t=5,3 T$.

Аналіз графічного матеріалу дав можливість зробити наступні висновки: із рис. 1 випливає, що максимальна величина прогинів по просторовій координаті (криві 3 індексом 2) зі зменшенням відношення 
$\left(E_{1}+E_{3}\right) /\left(2 E_{2}\right)$ стає більшою на $16 \%$; також суттєво змінюється якісна картина характеру коливань, які стають хвилеподібними. Більш суттєва різниця спостерігається для колових напружень по просторовій координаті $\sigma_{y y}^{c}$ (рис. 2). 3 грасріків видно, що для співвідношення (1) максимальне значення напруження $\sigma_{y y}^{c}$ досягає значення $4,4 \cdot 10^{5}$ Па (крива 3 індексом 2, зліва), а для співвідношення (2) таке ж напруження $\sigma_{y y}^{c}$ в 1,27 рази більше (крива з індексом 2, справа). Хвилеподібний характер коливань зберігається у випадку (2).

Розглянемо третій випадок. $h_{1}=h_{3}=1 \mathrm{mм} ; h_{2}=6 м \mathrm{~m}$; для $h_{1}$ модуль пружності $E_{1}=2 \cdot 10^{11} \Pi a$; щільність $\rho_{1}=7,8 \cdot 10^{3} \kappa 2 / \mathrm{M}^{3}$; для $h_{3}$ модуль пружності $E_{3}=7 \cdot 10^{10} \Pi а$; щільність $\rho_{3}=2,7 \cdot 10^{3} \mathrm{kz} / \mathrm{m}^{3}$; коефіцієнти Пуассона $v=0,33$; для $h_{2}$ відношення модулів пружності $\left(E_{1}+E_{3}\right) /\left(2 E_{2}\right)=50$ $\mathrm{i}\left(E_{1}+E_{3}\right) /\left(2 E_{2}\right)=500$, щільність $\rho_{2}=25 \mathrm{\kappa} / \mathrm{m}^{3}$, коефіцієнт Пуассона $v=0,3$.

На рис. 1 наведені порівняльні графіки максимальних прогинів коливальних процесів в серединній поверхні легкого заповнювача несиметричної циліндричної оболонки (криві з індексом 3). Криві максимальних прогинів побудовані аналогічно першим випадкам. Максимуми прогинів для другого випадку несиметричної конструкції тришарової структури досягаються при (1) $t=5,05 T$, а для (2) при $t=5,6 T$.

Аналіз графічного матеріалу дав можливість зробити наступні висновки: із рис. 1 випливає, що максимальна величина прогинів по просторовій координаті (криві 3 індексом 3) зі зменшенням відношення $\left(E_{1}+E_{3}\right) /\left(2 E_{2}\right)$ стає меншою на $52 \%$; також суттєво змінюється якісна картина характеру коливань, які стають більш хвилеподібними. Більш суттєва різниця спостерігається для колових напружень по просторовій координаті $\sigma_{y y}^{c}$ - (рис. 2). 3 графіків видно, що для співвідношення (1) максимальне значення напруження $\sigma_{y y}^{c}$ досягає значення $8,3 \cdot 10^{5} \Pi a$ (крива з індексом 3, зліва ), а для співвідношення (2) таке ж напруження $\sigma_{y y}^{c}$ в 1,89 рази менше (крива з індексом 3, справа). Хвилеподібний характер коливань зберігається у випадку (2).

Висновки. Завдяки отриманим залежностям максимальних прогинів серединної поверхні легкого заповнювача несиметричної тришарової циліндричної оболонки, як функції просторової координати, можливо помітити, що несиметричність тришарової структури значно впливає на іiї динамічну поведінку. Так у випаду коли імпульсне навантаження діє на сталевий несучий шар (рис. 1, криві 3), то зі зменшенням відношення $\left(E_{1}+E_{3}\right) /\left(2 E_{2}\right)$ максимальний прогин стає меншим на $14 \%$; а у випадку коли імпульсне навантаження діє на несучий шар з АМГ 7 (криві 2), то зі зменшенням відношення $\left(E_{1}+E_{3}\right) /\left(2 E_{2}\right)$ максимальний прогин стає більшим на $11 \%$; у випадку, коли імпульсне навантаження діє на симетричну 
тришарову циліндричну оболонку з легким заповнювачем (криві 1), то зі зменшенням відношення $E_{1} / E_{2}$ максимальні прогини збільшуються на $14 \%$. Якщо порівняти максимальні прогини для відношень модулів пружності (1) і (2), для симетричної структури (криві 1) і для несиметричної (криві 2, 3), то відношення складе $84 \%$ (1) і $41 \%$ (2). Ще більша різниця спостерігається для максимумів колових напружень по просторовій координаті $\sigma_{y y}^{c}$ (рис. 2) для відношень модулів пружності (1) і (2), для симетричної структури (криві 1) і для несиметричної (криві 2, 3). Відношення максимумів $\sigma_{y y}^{c}$ складе 2,63 рази (1) і 1,32 рази (2). Таким чином, можна зробити висновок, що використання «дискретно-структурного» підходу дає можливість детально дослідити динамічну поведінку несиметричних тришарових циліндричних оболонок з легким заповнювачем при нестаціонарних навантаженнях і вибрати раціональну конструкцію тришарової структури.

Перспективи подальшого розвитку у даному напрямку. Останнім часом в космічній галузі і будівництві широко використовуються тришарові оболонки з легким заповнювачем, підкріпленим ребрами жорсткості, розмір яких набагато менший ніж відстань між ними. В цьому напрямку $є$ незначна кількість робіт для обмеженого виду конструкцій і способів їх навантаження. На початковому стані знаходяться дослідження тришарових циліндричних пологих оболонкових будівельних конструкцій з легким заповнювачем, який підкріплений ребрами жорсткості [12]. Тому в подальших дослідженнях планується розробити теорію рівнянь, які могли б детально описати динамічну поведінку тришарових оболонок обертання з легким заповнювачем, армованим дискретними ребрами жорсткості.

\section{БІБЛІОГРАФІЧНІ ПОСИЛАННЯ}

1. Головко К.Г., Луговой П.З., Мейш В.Ф. Динамика неоднородных оболочек при нестационарных нагрузках / под ред. акад. НАН Украины А. Н. Гузя. К.: Изд. полиграф. центр «Киевский ун-т», 2012. 541 с.

2. Лычев C.A, Сидоров Ю.А. Нестационарные колебания трехслойных сферических оболочек с кратным спектром // Изв. вузов. Строительство. 2001. № 4. С. 31-39.

3. Лычев С.А., Сайфутдинов Ю.Н. Динамика трехслойной непологой сферической оболочки // Вестник ЧГПУ им. И.Я. Яковлева. Механика предельного состояния. 2007. № 2. С. 54-90.

4. Сеницкий Ю.Э., Лычев С.А. Динамика трехслойных сферических оболочек несимметричной структуры // Труды XVIII международной конференции по теории оболочек и пластин. Саратов. 1997. Т. 1. С.47-52.

5. Carrera E., Ciuffreda A. A unified formulation to assess theories of multilayered plates for various bending problems // Composite Structures. 2005. Vol. 69. No 3. P. 271293. DOI:10.1016/j.compstruct. 2004.07.003.

6. Frostig Y. , Thomsen O.T. Higher-order free vibration of sandwich panels with a flexible core // Int. J. of Solids and Structures. 2004. Vol. 41. P. 1697-1724. DOI: 10.1016/j.jjsolstr.2003.09.051. 
7. Kheirikhah M.M., Khalili S.M.R., Malekzadeh Fard K. Biaxial buckling analysis of soft-core composite sandwich plates using improved high-order theory // European Journal of Mechanics A/Solids. 2011. Vol.31. P. 54-66.

8. Lugovoi P.Z., Meish V.F. Dynamics of inhomogeneous shell systems under nonstationary loading (suevey) // Int. Appl. Mech. 2017. Vol. 3. No 5. P. 481-537

9. Malekzadeh Fard K., Livani M., Veisi A., Gholami M. Improved high-order bending analysis of double curved sandwich panels subjected to multiple loading conditions // Latin American J. of Solids and Structures. 2014. Vol. 11. P. 1591-1614.

10. Polyakov V., Shlitsa R., Chatys $R$. Eigenfrequencies of radial vibrations of a spherical sandwich shell // Mechanics of Composite Materials. 2008. Vol. 44. No 6. P. 591-600.

11. Shul'ga N.A., Meish V.F., Khamrenko Yu.A. Nonstationary oscillations of threelayer cylindrical shells under axisymmetric loading // Int. Appl. Mech. 1999. Vol. 35. No 8. P. 751-758.

12. Surianinov M., Yemelianova T., Shyliaiev O. Investigation of Free Vibrations of Three-Layered Circular Shell Supported by Annular Ribs of Rigidity // Materials Science Forum. Vol. 968. Actual Problems of Eng. Mech. 2019. P. 437-443.

https://doi.org/10.4028/www.scientific.net/MSF.968.437

13. Zarutskij V.A., Lugovoi P.Z., Meish V.F. Dynamic Problems and Stress Strain State of Inhomogeneous Shell Structures under Stationary and Nonstationary Loads // Int. Appl. Mech. 2009. Vol.45. No. 3. P. 245-272.

УДК 539.3

\author{
С. П. Орленко
}

\title{
ВЛИЯНИЕ НЕСИММЕТРИИ ТЕХСЛОЙНЫХ ЦИЛИНДРИЧЕСКИХ ОБОЛОЧЕК С ЛЕГКИМ ЗАПОЛНИТЕЛЕМ НА ИХ НАПРЯЖЕННО-ДЕФОРМИРОВАННОЕ СОСТОЯНИЕ ПРИ НЕСТАЦИОНАРНЫХ НАГРУЗКАХ
}

Получены уравнения колебаний несимметричной трехслойной цилиндрической оболочки с легким заполнителем при нестационарной нагрузке. При анализе элементов упругой структуры используется модель теории оболочек Тимошенко для каждого слоя. Численные результаты о напряженодеформированном состоянии несимметричной трехслойной упругой структуры получены с помощью метода конечных элементов. Исследовано влияние физико-механических параметров слоев оболочки на ее напряженодеформированное состояние при внутренней импульсной нагрузке.

Ключевые слова: несимметричная трехслойная цилиндрическая оболочка; легкий заполнитель; нестационарная нагрузка; напряженно-деформированное состояние; анализ численных результатов.

UDC 539.3

\author{
S. P. Orlenko
}

THE INFLUENCE OF THE ASYMMETRY

OF THREE-LAYERED CYLINDRICAL SHELLS WITH LIGHT FILLER ON THEIR STRSS-STRAIN STATE UNDER NON-STATIONARY LOADS 
The equation of oscillation of an asymmetric three-layered cylindrical shell with light filler under non-stationary loading is obtained. When analyzing the elements of the elastic structure, the model of Timoshenko's shell theory is used for each layer. Numerous results on the stress-strain state of an asymmetric three-layered elastic structure were obtained using the finite element method. The influence of the physical and mechanical parameters of the shell layers on its stress-strain state under internal impulse loading is investigated.

Keywords: asymmetric three-layered cylindrical shell; lightweight filler; non-stationary loading; stress-strain state; analysis of numerical results.

Layered shells are widely used in air, rocket, shipbuilding and in many other engineering and construction industries. The great attention is given for the development of the theory and methods of calculating the stressstrain state of layered structural elements under various influences. The need to perform a number of conflicting requirements simultaneously leads to the idea of developing multilayered structures in which each layer performs one or more of several functions. In this case, the layers may differ both in thickness and in physical and mechanical properties, that is, the package can be substantially heterogeneous. The complexity of solving such problems for layered systems stimulates the development of applied twodimensional theories. With significant values of differences between the physical and mechanical parameters of the layers, it is advisable to apply shell theories using independent hypotheses for each of the layers. In dynamic loads, in the layers there is a stress-strain state with significant gradients of displacements and stresses. In this paper, we consider threelayered cylindrical shells of symmetric and asymmetrical structure with light filler under non-stationary loading. Asymmetry of this structure is formed by bearing layers which are made of different materials. In the derivation of the solvable system of equations, the corresponding Timoshenko hypotheses for the shells and the variational principle of Hamilton - Ostrogradsky were used. A "discrete - structural" approach was applied to calculate the nonstationary oscillations of layered shells with a significant difference in the physical and mechanical characteristics of layers under non-stationary loads. The solution of specific problems with the help of the finite element method made it possible to investigate the influence of the asymmetry of the layered structure on its dynamic behavior under the action of impulse loading.

\section{REFERENCES}

1. Golovko K.G., Lugovoj P.Z., Mejsh V.F. Dynamics of inhomogeneous shells under unsteady loads / under the editorship of Acad. NAS of Ukraine A.N. Guz Kyiv: Ed.-polygraph. Center "Kiev University", 2012. 541 p. (in Russian).

2. Senickij YU.E., Lychev S.A. Dynamics of three-layer spherical shells of an asymmetric structure // Proceedings of the XVIII international conference on the theory of shells and plates. Saratov. 1997. Vol. 1. P. 47-52. (in Russian). 
3. Lychev, S.A., Sidorov Yu.A. Unsteady vibrations of three-layer spherical shells with multiple spectrum // Izv. universities. Building. 2001. No. 4. P. 31-39. (in Russian).

4. Lychev S.A., Sajfutdinov Yu.N. Dynamics of a three-layer non-canopy spherical shell // Bulletin of ChSPU them. I. Ya. Yakovleva, Mechanics of the Ultimate State. 2007. No. 2. P. 54-90. (in Russian).

5. Carrera E., Ciuffreda A. A Unified formulation to assess theories of multilayered plates for various bending problems // Composite Structures. 2005. Vol. 69. No 3. P. 271293. DOI:10.1016/j.compstruct. 2004.07.003.

6. Frostig, Y. and Thomsen, O.T. Higher-order free vibration of sandwich panels with a flexible core // Int. J. of Solids and Structures. 2004. Vol. 41. P. 1697-1724. DOI: 10.1016/j.ijsolstr.2003.09.051.

7. Kheirikhah M.M., Khalili S.M.R. and Malekzadeh Fard K. Biaxial buckling analysis of soft-core composite sandwich plates using improved high-order theory, European Journal of Mechanics A/Solids. 2011. 31. - P. 54-66.

8. Lugovoi P.Z., Meish V.F. Dynamics of inhomogeneous shell systems under nonstationary loading (suevey) // Int. Appl. Mech. 2017. Vol. 53, No. 5. P. 481-537.

9. Malekzadeh Fard K., Livani M., Veisi A. and Gholami M. Improved high-order bending analysis of double curved sandwich panels subjected to multiple loading conditions // Latin American J. of Solids and Structures. 2014. Vol. 11. P.1591-1614.

10. Polyakov V., Shlitsa R., Chatys $R$. Eigenfrequencies of radial vibrations of a spherical sandwich shell // Mechanics of Composite Materials. 2008. 44,№ 6. - P 591-600.

11. Shul'ga N.A., Meish V. F., Khamrenko Yu. A. Nonstationary oscillations of threelayer cylindrical shells under axisymmetric loading // Int. Appl. Mech. 1999. Vol. 35. No 8. P. 751-758.

12. Surianinov M., Yemelianova T., Shyliaiev O. Investigation of Free Vibrations of Three-Layered Circular Shell Supported by Annular Ribs of Rigidity // Materials Science Forum Actual Problems of Eng. Mech. 2019. Vol. 968. P. 437-443.

https://doi.org/10.4028/www.scientific.net/MSF.968.437

13. Zarutskij V.A., Lugovoi P.Z., Meish V.F. Dynamic Problems and Stress Strain State of Inhomogeneous Shell Structures under Stationary and Nonstationary Loads // Int. Appl. Mech. 2009. Vol. 45. No 3. P. 245-272. 